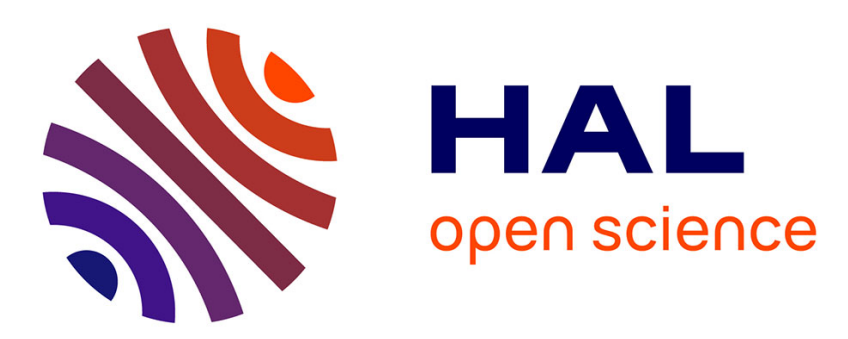

\title{
Multi-scale reliability analysis of composite structures â Application to the Laroin footbridge
}

\author{
Hocine Dehmous, Hélène Welemane
}

\section{To cite this version:}

Hocine Dehmous, Hélène Welemane. Multi-scale reliability analysis of composite structures â Application to the Laroin footbridge. Engineering Failure Analysis, 2011, vol. 18, pp. 988-998. 10.1016/j.engfailanal.2010.12.005 . hal-00758888

\section{HAL Id: hal-00758888 \\ https://hal.science/hal-00758888}

Submitted on 29 Nov 2012

HAL is a multi-disciplinary open access archive for the deposit and dissemination of scientific research documents, whether they are published or not. The documents may come from teaching and research institutions in France or abroad, or from public or private research centers.
L'archive ouverte pluridisciplinaire HAL, est destinée au dépôt et à la diffusion de documents scientifiques de niveau recherche, publiés ou non, émanant des établissements d'enseignement et de recherche français ou étrangers, des laboratoires publics ou privés. 


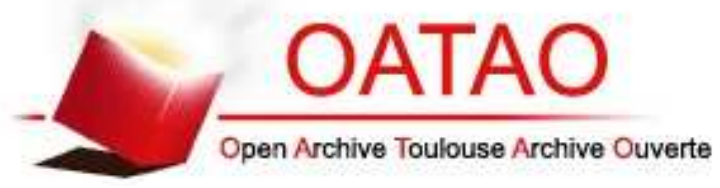

\section{Open Archive Toulouse Archive Ouverte (OATAO)}

OATAO is an open access repository that collects the work of Toulouse researchers and makes it freely available over the web where possible.

This is an author-deposited version published in: http://oatao.univ-toulouse.fr/ Eprints ID: 6577

To link to this article: DOI:10.1016/j.engfailanal.2010.12.005

URL: http://dx.doi.org/10.1016/j.engfailanal.2010.12.005

\section{To cite this version:}

Dehmous, Hocine and Welemane, Hélène Multi-scale reliability analysis of composite structures - Application to the Laroin footbridge. (2011) Engineering Failure Analysis, vol. 18 (n 3). pp. 988-998. ISSN 13506307 


\title{
Multi-scale reliability analysis of composite structures - Application to the Laroin footbridge
}

\author{
Hocine Dehmous ${ }^{\mathrm{a}}$, Hélène Welemane ${ }^{\mathrm{b}, *}$ \\ a Université de M'sila, BP 166, 28000 M'sila, Algeria \\ ${ }^{\mathrm{b}}$ Université de Toulouse;INP/ENIT;LGP;47, Avenue d'Azereix; F-65013 Tarbes, France
}

Keywords:

Structural reliability

Multi-scale analysis

Micromechanical modelling

Carbon-epoxy composite

\begin{abstract}
A B S T R A C T
This work aims at developing a new methodology for the reliability assessment of composite structures and their design optimization. It relies on the coupling of well established methods: homogenization scheme for the mechanical modelling of composite materials and reliability methods to account for their inherent variability. Moreover, such approach is based on an accurate treatment of inherent uncertainties of these mechanical systems at various scales, including microscopic and macroscopic levels, that provides new perspectives for structural design. As an illustration, we propose to apply the multi-scale reliability analysis on the case of the Laroin footbridge (France) with carbon-epoxy stay cables. Since the reliability assessment of such structure is evaluated through the fibre failure, numerical simulations require the coupling of reliability methods, finite element modelling to derive macroscopic loading within cables and micromechanics to estimate the effective elastic properties of composite and local responses within constituents. Results demonstrate the feasibility of the coupled approach at a structure scale and its main interests for the optimization phase of materials and engineering structures.
\end{abstract}

\section{Introduction}

Applications of fibre-reinforced composite materials were initially associated for the most part to aerospace and marine industries. Actually, their outstanding mechanical properties made them very attractive to many engineering contexts by providing new design perspectives [1]. Yet, important safety factors are still introduced to cover the important scatter of their mechanical properties, which could lead obviously to a major increase in the structure dimensions.

In this way, the recent development of structural reliability analyses has allowed significant progress: for the composite structures design first, by providing the range of use to achieve a specified reliability level and also, for the risk control by giving the security level of existing structures [2,3]. On the other hand, the specific mechanical response of heterogeneous materials has been widely explained by its microscopic features (properties of the constituents, phase geometry) [4]. In order to explain and analyze the influence of such aspects, micromechanics offer the most appropriate framework for the composite mechanical modelling since representations derive from the description of materials microstructure and from the physical mechanisms involved at their micro scale $[5,6]$.

The present contribution aims at associating reliability methods and micromechanical modelling in view of the design and optimization of composite structures. In order to represent scattering aspects introduced at the different scales of the structure, we integrate as random design variables both microscopic parameters of the composite material (constituents

\footnotetext{
* Corresponding author. Tel.: +33 (0)562442947; fax: +33 (0)562442708.

E-mail address: Helene.Welemane@enit.fr (H. Welemane).
} 
properties, fraction volume, ...) and macroscopic parameters of the structure (dimensions, loads, ...). In a previous work [7], this approach has been applied on a simple composite structure, namely a carbon-epoxy rod under longitudinal tension. The objective of this paper is to set up the same coupled analysis on a structure case through the reliability estimation of the composite stay cables of the Laroin footbridge (France). The objective is to extent the reasoning at a structure scale and also to put in evidence the new perspectives provided in the design field. Since the relevance of the approach relies on the availability of experimental characterizations, especially concerning the distribution of random parameters and the failure mode, the paper focuses on mechanical monotonic failure modes of the structure; long-term durability (fatigue or environmental effects) aspects are not considered.

\section{Description of the Laroin footbridge and composite rods}

\subsection{General description}

In 2002, FREYSSINET company has conceived and realized in Laroin the first cable-stayed structure in France including composite cables [8]. This pedestrian footbridge is composed of a steel deck, two reversed V-shaped pylons of $20.60 \mathrm{~m}$ height made of steel tubes, one high-strength steel holding stay cable for each pylon and its single span of $110 \mathrm{~m}$ length is maintained at each side by eight stay cables made of carbon-fibre-reinforced polymer (CFRP) composite (Figs. 1 and 2, [9]). These span stay cables are composed of a various number of strands: cables $\mathrm{H}_{1}$ and $\mathrm{H}_{2}$, nearest to the pylon, are composed of two composite strands and other cables $\mathrm{H}_{3}$ and $\mathrm{H}_{4}$ of three composite strands (Fig. 2), with each strand including seven parallel composite rods (6 mm diameter). Specific system of anchoring for the span stay cables has been developed by FREYSSINET, combining tightening effects (conical wedging) and friction effects (joining).

Each stay cable rod is a unidirectional carbon-epoxy composite manufactured by pultrusion by the SOFICAR company (Fig. 3). Fibres used are TORAYCA high-strength carbon fibres T 700-SC-12 K, embedded in an epoxy resin EPONAL 401 manufactured by BOSTIK FINDLEY with high fibre volume fraction (in the mean $f_{f}=67 \%$ ). Porosity within the resin is negligible (SOFICAR source). From the mechanical point of view, fibres exhibit transversally isotropic (around their axis given by unit vector $\mathbf{n}$, Fig. 3) brittle elastic behaviour and epoxy resin is isotropic viscoelastic [10,11]. In what follows, we consider small strain assumption, rate independent and isothermal conditions. Due to the predominance of fibres properties and the kind of load applied to the composite (longitudinal tension), the viscous aspect of matrix and the anisotropic behaviour of fibre can be neglected. Thus, the mechanical behaviour of each component is assumed to be isotropic linear elastic and typical elastic features are consequently the Young moduli ( $E_{m}$ for the matrix, $E_{f}$ for fibres) and Poisson ratios ( $v_{m}$ for the matrix and $v_{f}$ for fibres) where fibre data are relative to their axial direction (that is $E_{f}=E_{f}(\boldsymbol{n}), v_{f}=v_{f}(\boldsymbol{n}, \boldsymbol{t})$ whatever the unit vector $\boldsymbol{t}$ orthogonal to $\boldsymbol{n}$, Fig. 3). Moreover, since the matrix yield strain in axial tension is bigger than the one relative to fibres, the main strength characteristic of components is the fibre longitudinal tensile strength denoted $\sigma_{f}^{R}(\boldsymbol{n})$.

\subsection{Composite micromechanical modelling - Mori - Tanaka formulation}

Within linear elastic context, we have chosen the Mori-Tanaka estimate (i.e. the resin matrix is considered as the reference medium and is subjected to its own stress, see [6,12]). This model represents the material symmetry induced by reinforcement (through Eshelby tensor), accounts in some manner for phase interactions and leads to satisfactory results for such high fibre volume fraction unidirectional composites in agreement with experiments and finite element simulations.

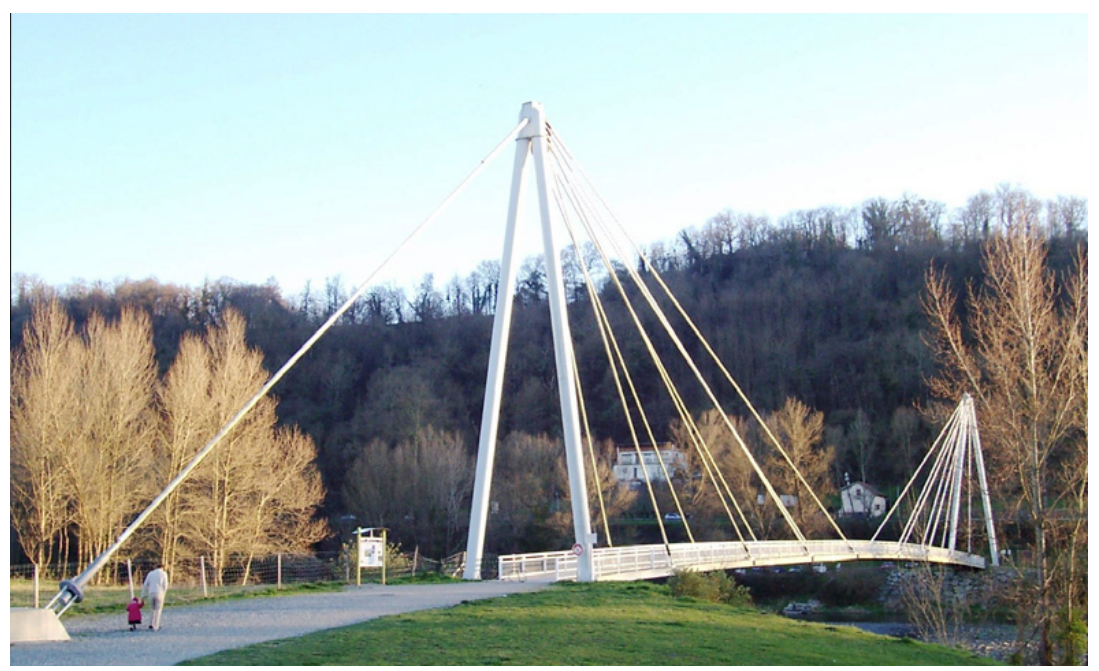

Fig. 1. Picture of the Laroin footbridge. 


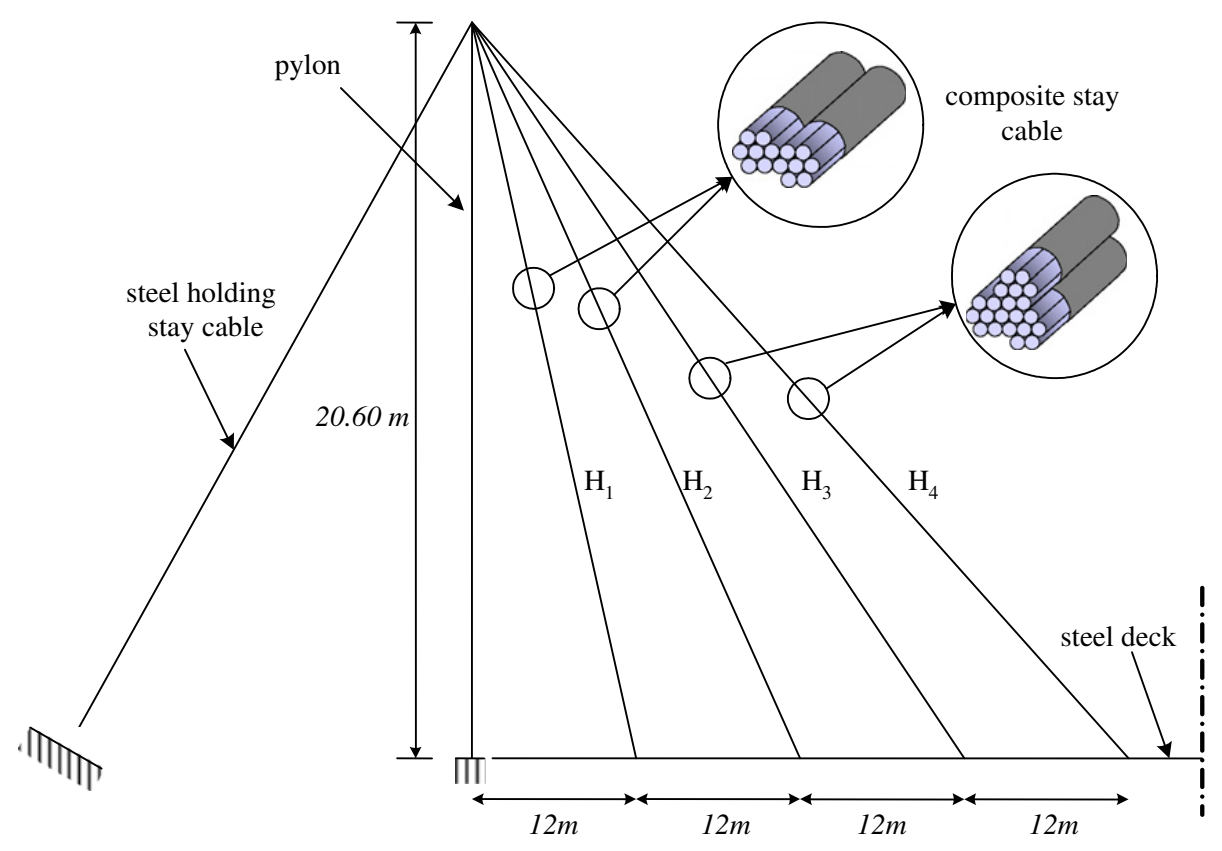

Fig. 2. Structure of composite stay cables.

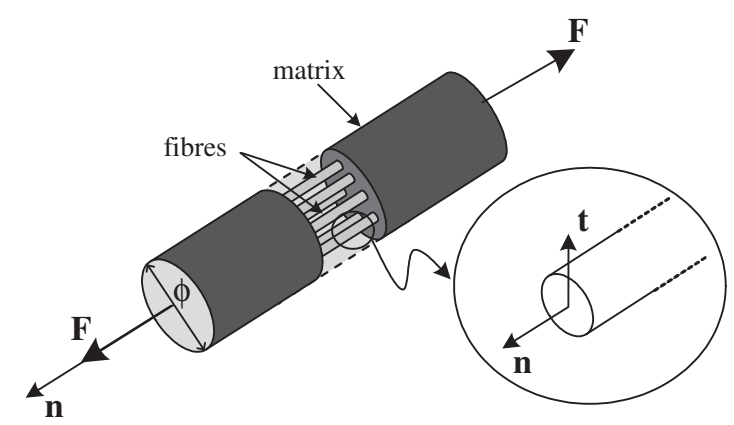

Fig. 3. Composite rod under longitudinal tension loading.

Moreover, it provides explicit expressions of the effective properties of the material representative volume element and also of the local fields within constituents (strain $\boldsymbol{\varepsilon}$ and stress $\boldsymbol{\sigma}$ ) when it is subjected to a macroscopic loading (strain $\mathbf{E}$ and/or stress $\boldsymbol{\Sigma}$ fields) [6]. This constitutes an important asset for the next structural analysis when the approach will be coupled with the finite element method.

The representative volume $V$ is composed of long identical cylindrical fibres (volume $V_{f}$ ) perfectly aligned along axis $\mathbf{n}$ and embedded in the homogeneous matrix; interfaces between constituents are supposed to be perfect. In this case, the effective stiffness tensor provided by the Mori-Tanaka scheme is given by:

$$
C_{\text {hom }}^{M T}=C_{(m)}+f_{f}\left(C_{(f)}-C_{(m)}\right):\langle A\rangle_{(f)}^{M T}
$$

$C_{(m)}$ and $C_{(f)}$ are the stiffness tensors respectively of the matrix and of fibre materials and $\langle A\rangle_{(f)}^{M T}$ is the average strain concentration tensor for the fibre phase $\left(\langle\boldsymbol{\varepsilon}\rangle=\frac{1}{\left|V_{f}\right|} \int_{V_{f}} \boldsymbol{\varepsilon} d V=\langle A\rangle_{(f)}^{M T}: \mathbf{E}\right)$ given by:

$$
\langle A\rangle_{(f)}^{M T}=\left[I+S_{(m)}^{E}: C_{(m)}^{-1}:\left(C_{(f)}-C_{(m)}\right)\right]^{-1}:\left[\left(1-f_{f}\right) I+f_{f}\left[I+S_{E}^{(m)}: C_{(m)}^{-1}:\left(C_{(f)}-C_{(m)}\right)\right]^{-1}\right]^{-1}
$$

where the Eshelby tensor of the inhomogeneity $S_{(m)}^{E}$ depends on the matrix elastic properties and vector $\mathbf{n}$ [5], and $I$ denotes the symmetric fourth-order identity tensor. Moreover, the average local stress over the fibre phase $\langle\boldsymbol{\sigma}\rangle_{(f)}=\frac{1}{\left|V_{f}\right|} \int_{V_{f}} \boldsymbol{\sigma} d V$ is such that:

$$
\langle\boldsymbol{\sigma}\rangle_{(f)}=C_{(f)}:\langle A\rangle_{(f)}^{M T}:\left(C_{\text {hom }}^{M T}\right)^{-1}: \Sigma
$$

Accordingly, the effective properties of the transversally isotropic (with axis $\mathbf{n}$ ) composite material and the local field $\langle\boldsymbol{\sigma}\rangle_{(f)}$ can be expressed directly from the matrix and fibres elastic properties $\left(E_{m}, E_{f}, v_{m}, v_{f}\right)$, the fibre volume fraction $f_{f}$ and the macroscopic loading $\boldsymbol{\Sigma}$. 


\section{Coupled micromechanical-reliability analysis - Application to the composite rod}

The coupled micromechanical-reliability approach has been previously applied at a material scale on the composite rod which represents the elementary part of the stay cables [7]. In this section, the different steps and results of such analysis are recalled as they will provide basic elements for the following work.

\subsection{Reliability model}

The first step of a structural reliability analysis consists in defining the input vector $X=\left\{X_{i}\right\}_{i=1 \ldots N}$ that describes the random variation of the $N$ different structure design parameters $X_{i}$. Information required to characterize their distribution is the joint probability density function $f_{X}$, otherwise marginal density function relative to each variable and correlation relations. Here, two kinds of uncertainties have been retained and statistically defined according to experimental data of manufacturers:

- at the microscopic level, namely the constituent elastic properties $E_{m}, v_{m}$ and $E_{f}, v_{f}$ (respectively BOSTIK and TORAY sources), the fibre strength $\sigma_{f}^{R}(\mathbf{n})$ (TORAY source) and the fibre volume fraction $f_{f}$ (SOFICAR source),

- at the macroscopic level, namely the rod diameter $\phi$ (SOFICAR source).

Precisely, the statistical analysis done by manufacturers has shown a Normal distribution for these seven random design variables with mean value $\bar{X}_{i}$ and standard deviation $S_{X_{i}}$ given in Table 1 . Note that the kind of distribution retained does not modify the general methodology presented here (association of micromechanics and reliability methods). Moreover, in case of a lack of experimental data, it would be even relevant to realize some parametric analysis with respect to the random variables distributions.

The second requirement is the definition of a failure scenario mathematically represented by a limit state function $G$ : $G(X)=0$ denotes the limit state surface, that is the boundary between the safe domain $D_{s}$ (such that $G(X)>0$ ) and the failure domain $D_{f}$ (such that $G(X) \leqslant 0$ ). As said before, the coupled approach presented here is physically justified by the use of statistical experimental characterizations to define the random parameters (constituents, composite material, loading). In the same spirit, the failure mode considered in this study is restricted to monotonic loadings since the information available on the composite failure mode (provided by TORAY and SOFICAR) concerns only such kind of loading without specific environmental effects. Fibre-reinforced composite materials with polymeric matrices submitted to longitudinal tension have their strength determined basically by the strength of their fibres, which mainly carry axial loads and tend to fail in a brittle manner. The failure is then associated to fibre breakage and the limit state function $G$ is classically defined as follows:

$$
G=\sigma_{f}^{R}(\mathbf{n})-\left\langle\sigma_{I}\right\rangle_{(f)}
$$

where $\left\langle\sigma_{I}\right\rangle_{(f)}$ represents the maximum principal value of the average stress in fibres. Note that the use of micromechanics for the mechanical modelling allows at this stage the account of the physical origin of failure and confers a clear meaning to the reliability definition.

The calculation of reliability indicators which provide a quantitative and qualitative evaluation of the structure reliability constitutes the last step of the analysis. Theoretically, the probability of failure $P_{f}$ is defined by the following integral:

$$
P_{f}=\int_{D_{f}} f_{X}(x) \prod_{i=1}^{N} d x_{i}
$$

Like most mechanical systems, this integral cannot be computed analytically $\left(f_{X}\right.$ is not available, $D_{f}$ has an implicit definition since average local stress $\left\langle\sigma_{I}\right\rangle_{(f)}$ depends on random variables $X$ ) and numerical methods should be employed. For very small values of $P_{f}$ (less than $10^{-2}$ ), an accurate estimation of $P_{f}$ with Monte Carlo simulation method would be computationally expensive (at least $10^{4}$ simulations). So, it clearly seems more pertinent to turn towards approximation methods that rely on simplifications of the failure domain: First Order Reliability Method (FORM) or Second Order Reliability Method (SORM) (see

Table 1

Random variables $\left\{X_{i}\right\}_{i=1,8}$ considered in rod reliability analysis.

\begin{tabular}{llll}
\hline Variables & & Mean value $\bar{X}_{i}$ & Standard deviation $S_{X_{i}}$ \\
\hline Matrix Young modulus (MPa) & $E_{m}$ & 2800 \\
Matrix Poisson ratio & $v_{m}$ & 0.4 & 42 \\
Fibre Young modulus (MPa) & $E_{f}$ & 230000 \\
Fibre Poisson ratio & $v_{f}$ & 0.3 \\
Fibre tensile strength (MPa) & $\sigma_{f}^{R}(\mathbf{n})$ & 4870 \\
Fibre volume fraction (\%) & $f_{f}$ & 67 \\
Rod diameter (mm) & $\phi$ & 6 & 7667 \\
Active fibres proportion (\%) & $p_{a c t}$ & 95 \\
\hline
\end{tabular}


detailed explanation in Refs. [2,3]). These techniques are based on a transformation of the parameters from the variables space $X=\left\{X_{i}\right\}_{i=1 \ldots N}$ into a standard Normal one $U=\left\{U_{i}\right\}_{i=1 \ldots N}$ where the limit state function $H$ is approximated by a linear (FORM) or quadratic (SORM) function around the design point $P^{*}$ (most probable failure point). The failure probability, deduced from this approximate surface, can be directly computed from the reliability index $\beta$ (distance between the Normalized space origin $0_{U}$ and $P^{*}$, Fig. 4) obtained by an optimization process. In addition to their computational efficiency, these methods provide a sensitivity analysis of design parameters and help the conception phase, quality control or even to reduce the problem size. Precisely, one can get the importance factors (or weights) $\left\{\alpha_{i}\right\}_{\mathrm{i}=1 \ldots N}$ that quantify the dependence at the conception point $P^{*}$ of the reliability index $\beta$ regarding each Normalized random variables $U_{i}$ :

$$
\alpha_{i}=-\frac{\partial \beta}{\partial U_{i}}\left(P^{*}\right), \quad \forall i \in[1 \ldots N]
$$

The more $\left|\alpha_{i}\right|$ is important, the more $X_{i}$ plays a significant stochastic role; moreover, if $\alpha_{i} \leqslant 0$ (respectively $\alpha_{i}>0$ ), $X_{i}$ is considered as a strength variable (resp. loading variable) for which an increase in its mean value induces an increase (resp. a decrease) of the structure reliability. To complete such analysis, it is also interesting to derive the elasticities $\left\{e_{r_{i}}\right\}_{i=1 \ldots N}$ according to distribution parameters of each random variables (here the mean value $r_{i}=\bar{X}_{i}$ or the standard deviation $r_{i}=S_{X_{i}}$ ) defined by:

$$
e_{r_{i}}=\frac{r_{i}}{\beta} \frac{\partial \beta}{\partial r_{i}}\left(P^{*}\right), \quad \forall i \in[1 \ldots N]
$$

Such parameter precises the amplitude of the modification of index $\beta$ at the conception point $P^{*}$ when the parameter $r_{i}$ fluctuates, with the same tendency of $\alpha_{i}$ regarding their sign.

Practically, numerical simulations have been performed by a direct coupling between the probabilistic software FERUM (Finite Element Reliability Using Matlab [13]) and the micromechanical model presented before. For a given value of the macroscopic loading $\boldsymbol{\Sigma}$, FERUM generates realizations of the random vector $X$ and the micromechanical model provides the related average local stress in the fibres (macro to micro). FERUM can finally evaluate the function $G$ and its derivatives necessary for the determination of reliability index $\beta$ and for the sensitivity analysis.

\subsection{Rod analysis results}

The predicted failure probability $P_{f}$ of the composite rod under longitudinal tension load $F$ (that is $\boldsymbol{\Sigma}=\Sigma_{n n} \mathbf{n} \otimes \mathbf{n}$ with $\Sigma_{n n}=\frac{4 F}{\pi \phi^{2}}$ ), derived from the previously described micromechanical model (denoted basic), is compared with experimental tests data carried out by SOFICAR (158 experimental measures, Fig. 5). Note that simulations with FORM and SORM methods lead to same values of $P_{f}$ (precision of $10^{-3}$ ) for around 50 calls to the limit state function $G$. The investigation of various potential origins of the important gap between theoretical and experimental results is detailed in Ref. [7]. The sensitivity analysis of the model formulation and its parameters stands in agreement with the SOFICAR expertise: such difference can be explained by fibre damage or misalignment induced by the manufacturing process; thus, only a fraction $p_{a c t}$ of the fibres (called active fibres) really participate to the composite behaviour and strength. A corrected formulation of the micromechanical model is then established such that the fibre volume fraction becomes equal to $f_{f} \times p_{\text {act }}$ with $p_{\text {act }}$ a new random variable. This eighth variable is identified strictly independently on different products of Soficar (carbon-epoxy composite laminates for concrete structure reinforcement) and its distribution parameters are given in Table 1 (in accordance with others variables, a Normal distribution has been chosen [7]). The new theoretical curve drawn in Fig. 5 shows a clear improvement in the representation and justifies the choice of the corrected model in what follows.
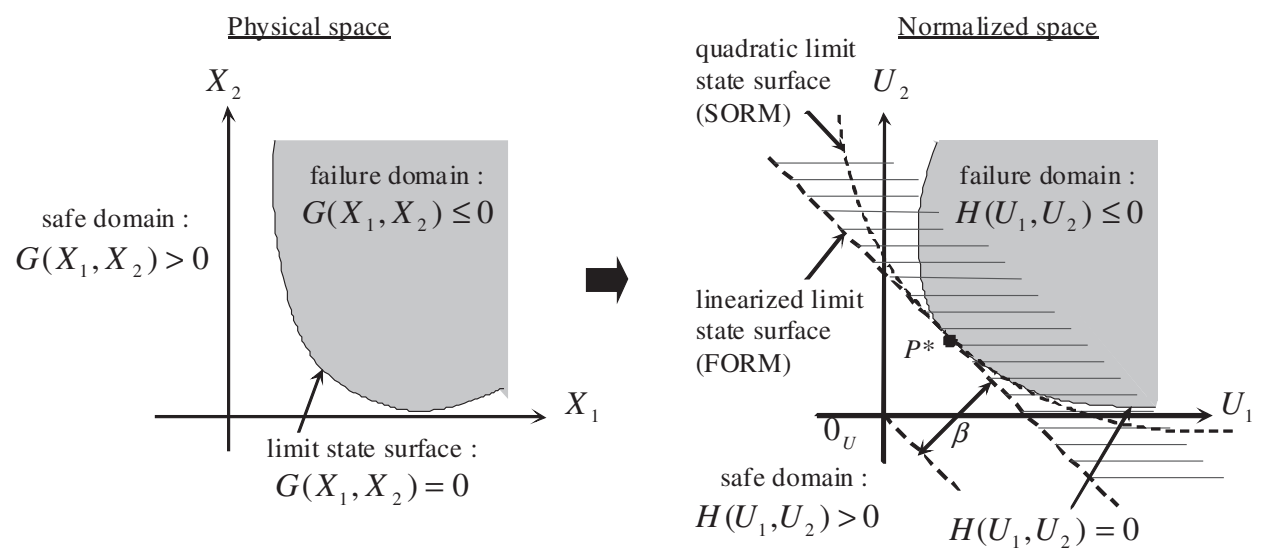

Fig. 4. Definition of the approximation methods and reliability index $\beta$. 


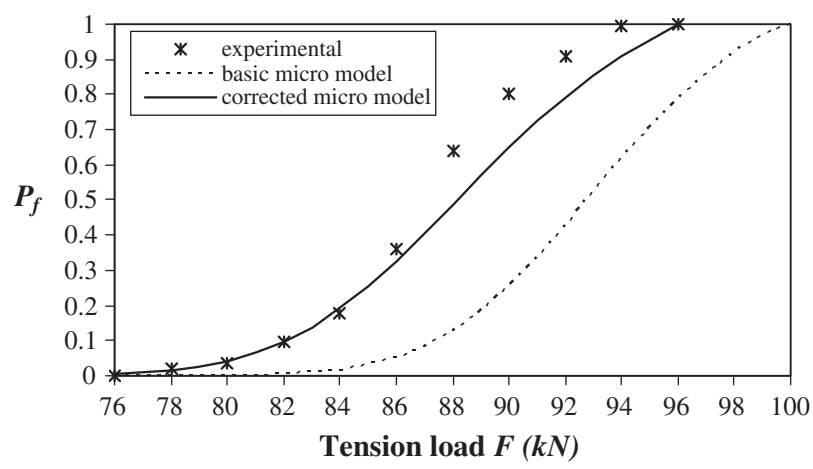

Fig. 5. Failure probability of carbon-epoxy rod.

Finally, the sensitivity analysis is performed to identify the role of the different design variables. Fig. 6 shows that the scatter of the fibre strength $\sigma_{f}^{R}(\mathbf{n})$, the fibre volume fraction $f_{f}$, the active fibre fraction $p_{a c t}$ and the diameter $\phi$ of the rod represent the most important parameters for the rod reliability; uncertainties on the constituents elastic properties $\left(E_{m}, E_{f}, v_{m}\right.$, $v_{f}$ ) have not much influence on the rod probability of failure. This information will help again for the further random variables selection.

\section{Coupled micromechanical-reliability analysis - Application to the stay cables of the Laroin footbridge}

Contrary to steel elements that exhibit a ductile safety margin, the brittle character of the failure of composite stay cables makes them appear as the weakest point of the footbridge. In order to estimate the structure reliability, it seems then relevant to study first the reliability of such composite elements. In this part, we intend to detail the three steps of the probabilistic model definition for the stay cables reliability analysis. Even if we pursue the reasoning presented above on the rod case, this preparation work needs specific explanations in view of the multi-scale approach retained.

\subsection{Random variables}

Owing to the complexity involved, a complete description of all uncertainties is clearly not compatible with an efficient modelling of the system. Therefore, the problem is restricted to the uncertainties relative to the stay cables; other structure elements are modelled in a deterministic way. Precisely, uncertainties affecting stay cables concern both the microscopic level (composite material) and the macroscopic level (structure):

- their mechanical behaviour, or equivalently the one of its elementary parts, i.e. the composite rods; in this way, the previous analysis has shown the relevance of the corrected micromechanical model and allows a great reduction in the problem size since only significant parameters put in evidence in Section 3 are selected $\left(\sigma_{f}^{R} \mathbf{n}, f_{f}\right.$ and $\left.p_{\text {act }}\right)$; constituents elastic properties $\left(E_{m}, E_{f}, v_{m}, v_{f}\right)$ are chosen deterministic and take their mean value given in Table 1;

- their geometry and especially their section since the diameter $\phi$ of the rod appears also as an important feature (question of length is not a determining point due to the cables adjustment phase, see after); yet, as the number of rods differs between cables $\left\{H_{i}\right\}_{i=1,2}$ and $\left\{H_{i}\right\}_{i=3,4}$, we consider directly their respective total section $\mathrm{A}$ as the typical random geometric variable whose statistical distribution parameters are identified from those of $\phi$;

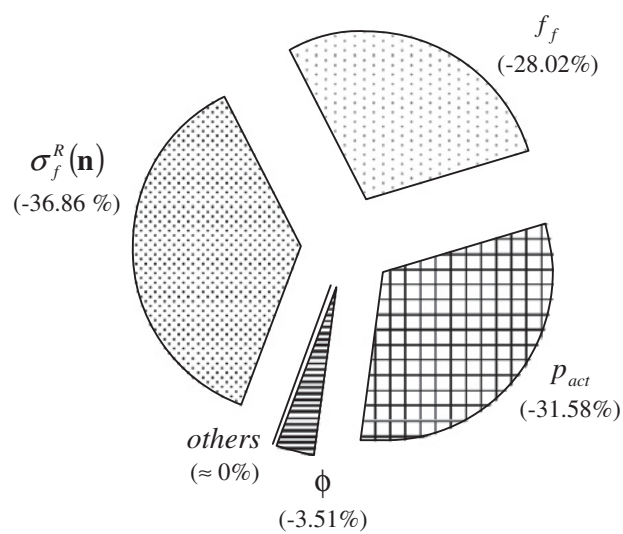

Fig. 6. Composite rod analysis - Importance factors $\alpha_{i}$ associated to random variables. 
- their connections with the pylon and longitudinal steel guider; the anchorage system developed by FREYSSINET which associates tightening and friction effects leads to a very complex failure scenario that would deserve itself a specific reliability analysis; in this study, perfect connections have been assumed between elements;

- their mechanical loading induced by the footbridge loading. Focusing on the exploitation phase, the footbridge is a civil engineering structure subjected to two kinds of loads. Firstly, the permanent ones: its weight (denoted $P P$ ) and adjustment forces (denoted $\left\{F_{0}^{H_{i}}\right\}_{i=1,4}$ and given by rod in each stay cable $\left\{H_{i}\right\}_{i=1,4}$ ). The latter are applied to maintain each stay cable in a tension state whatever loads applied and calculated by considering the weight of cables and the equilibrium of structure under permanent load. Then, variables loads include exploitation load, wind and temperature. All different loading cases imposed by current rules for the design of bridge structures have been beforehand investigated in a deterministic context in order to define the most unfavourable combinations for each set of cables $\left\{H_{i}\right\}_{i=1,2}$ and $\left\{H_{i}\right\}_{i=3,4}$ [7]; from this, we find that such critical cases are related only to exploitation load $Q$ and that stay cables $\mathrm{H}_{2}$ and $\mathrm{H}_{4}$ are respectively always more charged than $\mathrm{H}_{1}$ and $\mathrm{H}_{3}$.

Accordingly, Table 2 sums up the ten random variables considered in this part: the statistical distribution of composite microstructural parameters and geometric parameter comes from the rod study (Section 3); without specific data, we assume a Normal distribution for various loadings (any other distribution derived from a precise statistical study could be used while keeping the same global reasoning). Their mean value comes from the footbridge description for the permanent weight $P P$, from the adjustment study for $\left\{F_{0}^{H_{i}}\right\}_{i=1,4}$ and technical rules provide the mean intensity $\bar{Q}$ for the exploitation load which depends on the charged length [7]. Concerning the standard deviation, we consider about $10 \%$ of the mean value in view of important uncertainties affecting these parameters. Note finally that the number of random variables (10) remains compatible with the direct coupling employed thereafter; reliability calculations should not be too time-consuming.

\subsection{Failure criterion}

Stay cables are subjected to longitudinal tension, so as composite rods; the failure mode remains therefore associated with the fibre failure as in Section 3. Insomuch as experimental tests on fibres and on composite rods require cylindrical samples of the same size (200 mm length), no scale effect was considered for the rod study. Here this question would require more attention since the length of stay cables is comprised between $20 \mathrm{~m}$ and $53 \mathrm{~m}$. Yet, existing investigations of this effect (for example [14]) do not consider such length amplitude and it is quite difficult to estimate reasonably the scale effect in present conditions. Thus, we assume for the structure analysis that the fibre properties, especially their longitudinal tensile strength $\sigma_{f}^{R}(\mathbf{n})$, are still the ones identified by TORAY. In accordance with the objectives of the coupled approach, in particular to account for the microstructural origin of failure even for problems at the structure scale, we keep consequently the limit function $G$ used before for the material study and defined in Eq. (4).

\subsection{Reliability calculations}

Again the expression of the failure criterion is implicit through the average local stress in fibres. In comparison to Section 3, the macroscopic loading applied to rod arises here from the structural analysis of the footbridge, generally realized by finite element method [3]. In this aim, a three dimensional model is established for the Laroin footbridge with finite element code ABAQUS. Two kinds of elements have been used for the different structural parts: steel girders, transversal beams and the two pylons have been modelled with elastic beam elements; transversal stiffness and all stay cables (since they are

Table 2

Random variables $\left\{X_{i}\right\}_{i=1,10}$ considered in footbridge reliability analysis.

\begin{tabular}{|c|c|c|c|}
\hline Variables & & Mean value $\bar{X}_{i}$ & Standard deviation $S_{X_{i}}$ \\
\hline \multicolumn{3}{|c|}{ Composite microstructural parameters } & 162 \\
\hline $\begin{array}{l}\text { Fibre volume fraction (\%) } \\
\text { Active fibres proportion (\%) }\end{array}$ & $\begin{array}{l}f_{f} \\
p_{a c t}\end{array}$ & $\begin{array}{l}67 \\
95\end{array}$ & $\begin{array}{l}2 \\
3\end{array}$ \\
\hline $\begin{array}{l}\text { Geometric parameter } \\
\text { Section } \mathrm{H}_{1} \text { and } \mathrm{H}_{2}\left(\mathrm{~mm}^{2}\right) \\
\text { Section } \mathrm{H}_{3} \text { and } \mathrm{H}_{4}\left(\mathrm{~mm}^{2}\right)\end{array}$ & $\begin{array}{l}\text { A } \\
\text { A }\end{array}$ & $\begin{array}{l}395.8 \\
593.8\end{array}$ & $\begin{array}{l}4.8 \\
7.1\end{array}$ \\
\hline $\begin{array}{l}\text { Loadings } \\
\text { Permanent load }(\mathrm{N} / \mathrm{m})\end{array}$ & $P P$ & 10650 & 1065 \\
\hline \multicolumn{3}{|l|}{ Adjustment forces $(\mathrm{kN})$} & 0.40 \\
\hline Rod in stay cable $\mathrm{H}_{2}$ & $F_{0}^{H_{2}}$ & 4.64 & 0.46 \\
\hline Rod in stay cable $\mathrm{H}_{3}$ & $F_{0}^{H_{3}}$ & 4.05 & 0.40 \\
\hline Rod in stay cable $\mathrm{H}_{4}$ & $F_{0}^{H_{4}}$ & 4.38 & 0.43 \\
\hline Exploitation load (N/m) & $Q$ & $\bar{Q}$ & $10 \% \bar{Q}$ \\
\hline
\end{tabular}


primarily designed to sustain tension forces) have been represented by truss elements. For the boundary conditions, the pylons bases are embedded and elastic supports are considered at the two ends of the girders (in axial and transversal ways). As said before, connections between the cables and the steel girders are considered as perfect.

From this, the question is to ensure a dialog between the probabilistic tool (generation of the random variables, reliability index $\beta$ calculation, sensitivity analysis, ...) and the mechanical tool (evaluation of $G$ and its gradients). We set up a direct coupling between the probabilistic software FERUM and the finite element software ABAQUS where the micromechanical model plays two roles (Fig. 7):

- micro to macro (homogenization): for each realization of the random vector $X$, it provides the effective elastic properties of the composite from Eq. (1); at this stage, the description of the mechanical model is thus complete and one can call upon ABAQUS to deduce the macroscopic loading induced in the different parts of the structure, especially the macroscopic stress $\boldsymbol{\Sigma}$ applied to the rods of each stay cable;

- macro to micro (localization): from $\boldsymbol{\Sigma}$, the micromechanical model gives then access to the average local stress in the fibres $\left\langle\sigma_{I}\right\rangle_{(f)}$ and FERUM has the whole data to evaluate the function $G$.

These various steps are repeated until the convergence of the optimization algorithm leading to the index $\beta$. Moreover, in order to ensure the safety of other structural elements, a verification that metallic parts remain in the elastic domain is systematically carried out for each simulation.

\section{Results and discussion}

\subsection{Failure probability of the Laroin footbridge stay cables}

Reliability analysis is performed for each stay cables $\mathrm{H}_{2}$ and $\mathrm{H}_{4}$ by considering the corresponding most unfavourable loading case. As a matter of fact, failure probabilities are so low that only the FORM method provides some results (convergence is not obtained with SORM) with a reasonable number of calls to function $G$, namely of 576 calls for cable $\mathrm{H}_{2}$ and 288 calls for $\mathrm{H}_{4}$, in comparison to Monte Carlo method that would require at least $10^{42}$ simulations. Moreover, simulation results are given in terms of the reliability index $\beta$ which is more representative than values of $P_{f}$, namely $\beta=20.00$ for cable $\mathrm{H}_{2}$ and $\beta=19.76$ for $\mathrm{H}_{4}$. If we compare to the values generally accepted in civil engineering (that is $3 \leqslant \beta \leqslant 7$ ), reliability indices found are far above those usually obtained. This can be explained to a large extent by the safety margin kept by designers in view of the long-term durability or anchorage effects that can substantially affect the structure reliability. Accordingly, the

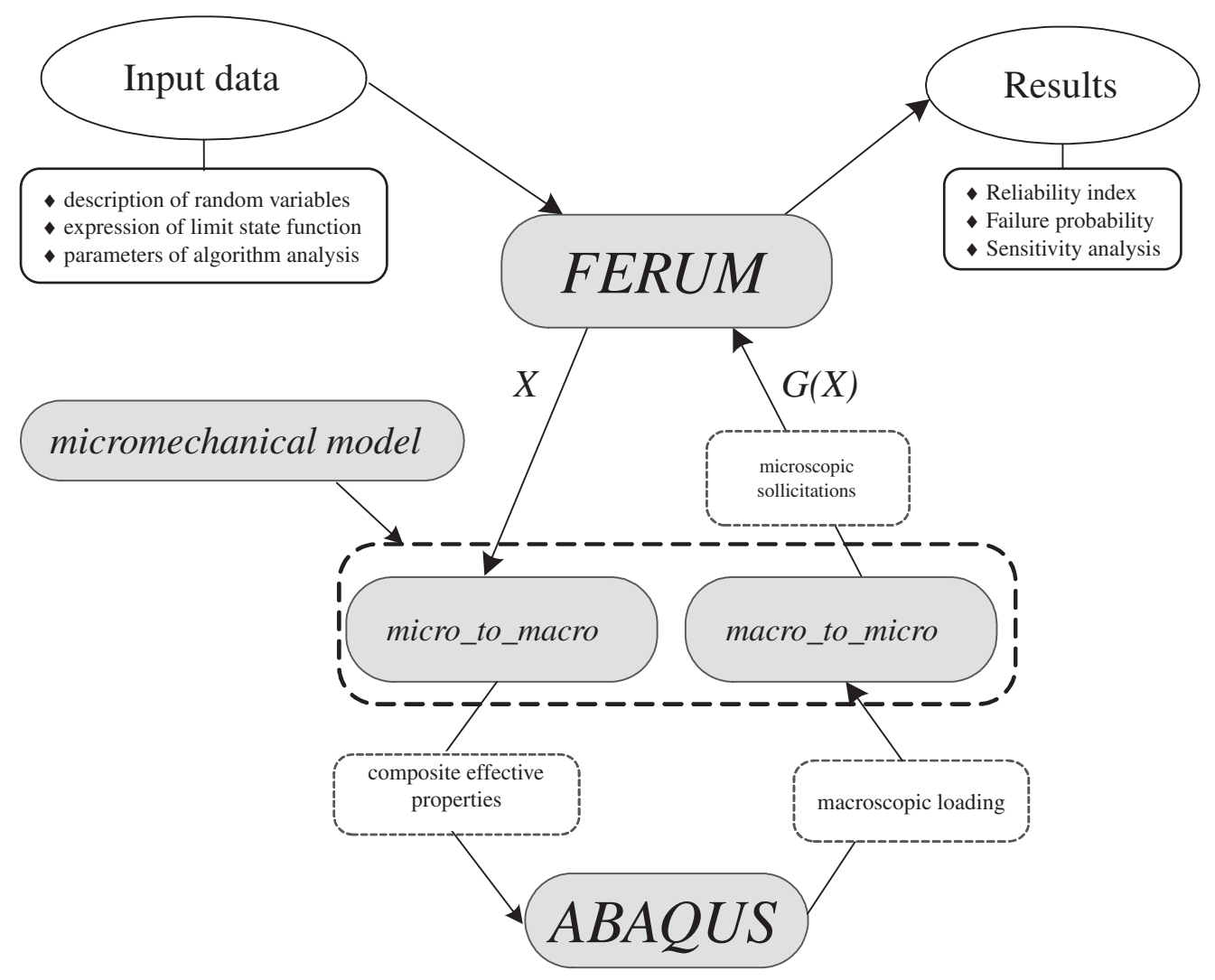

Fig. 7. FERUM-ABAQUS direct coupling. 
aim is clearly not to conclude in the absolute sense but rather to show the interest for optimization solutions by analyzing $\beta$ indices in relative terms from this current state.

Importance factors presented in Fig. 8 show that the scatter in the fibre tensile strength $\sigma_{f}^{R}(\mathbf{n})$, fibre volume fraction $f_{f}$, active fibres proportion $p_{a c t}$, permanent weight $P P$ and exploitation load $Q$ has the most significant influence on the stay cables reliability (the total weight of these variables represents 95\%). On the other hand, the adjustment forces $\left\{F_{0}^{H_{i}}\right\}_{i=1,4}$ have so neglecting effect that they can be treated as deterministic in future reliability analyses. From this, one can conclude also that the statistical distribution of the fibre tensile strength is of main importance compared to others; it is then relevant to base such description on a complete experimental characterization of their properties (such as done by TORAY).

\subsection{Risk control and design optimization of composite stay cables}

Fig. 9 presents first the sensitivity of the probability of failure with respect to the standard deviation of variables. These results specify the origin of major scatterings in the structure response and then help to avoid or at least to limit them through quality control. The coupled approach allows here to demonstrate the influence of rod control at different scales that is at different steps of the manufacturing process: from the fibres manufacturing phase $\left(\sigma_{f}^{R}(\mathbf{n})\right)$ to the composite manufacturing phase $\left(f_{f}, p_{a c t}, A\right)$. Again, the significant impact of the fibre tensile strength is highlighted, which recommends to pay a particular attention to this manufacturing step.

Let now illustrate the capacities of the coupled approach for the structure optimization. For this, the sensitivities of the probability of failure with respect to the mean value of random variables provide interesting guidelines by indicating the parameters to change in order to enhance or reduce the reliability level.

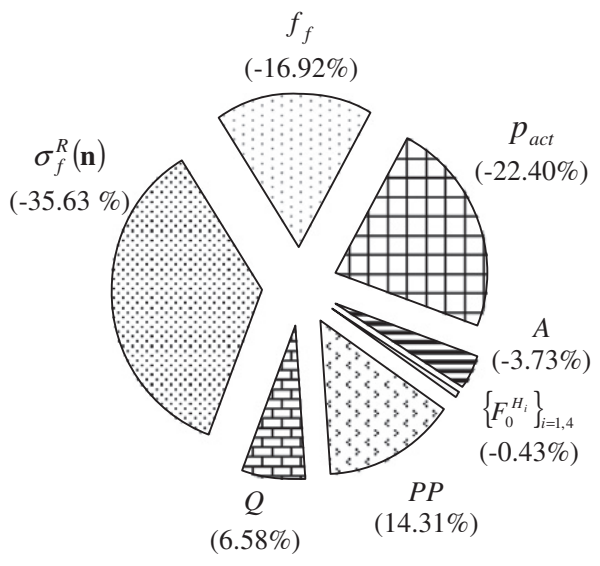

(a) stay cable $\mathrm{H}_{2}$

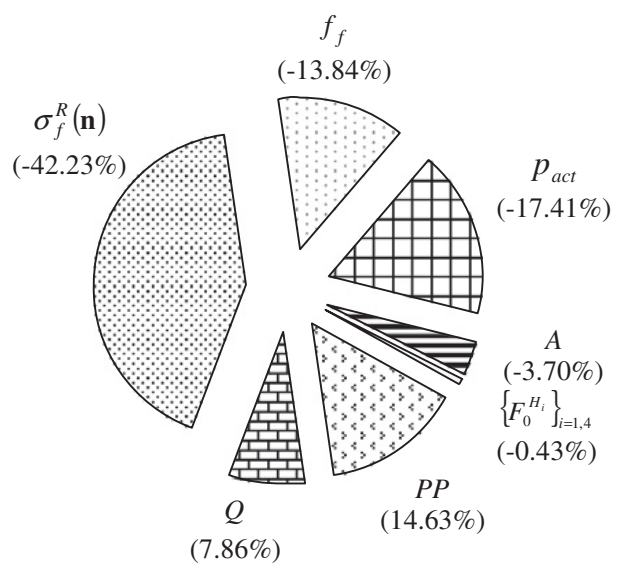

(b) stay cable $\mathrm{H}_{4}$

Fig. 8. Footbridge analysis - Importance factors $\alpha_{i}$ associated to random variables.

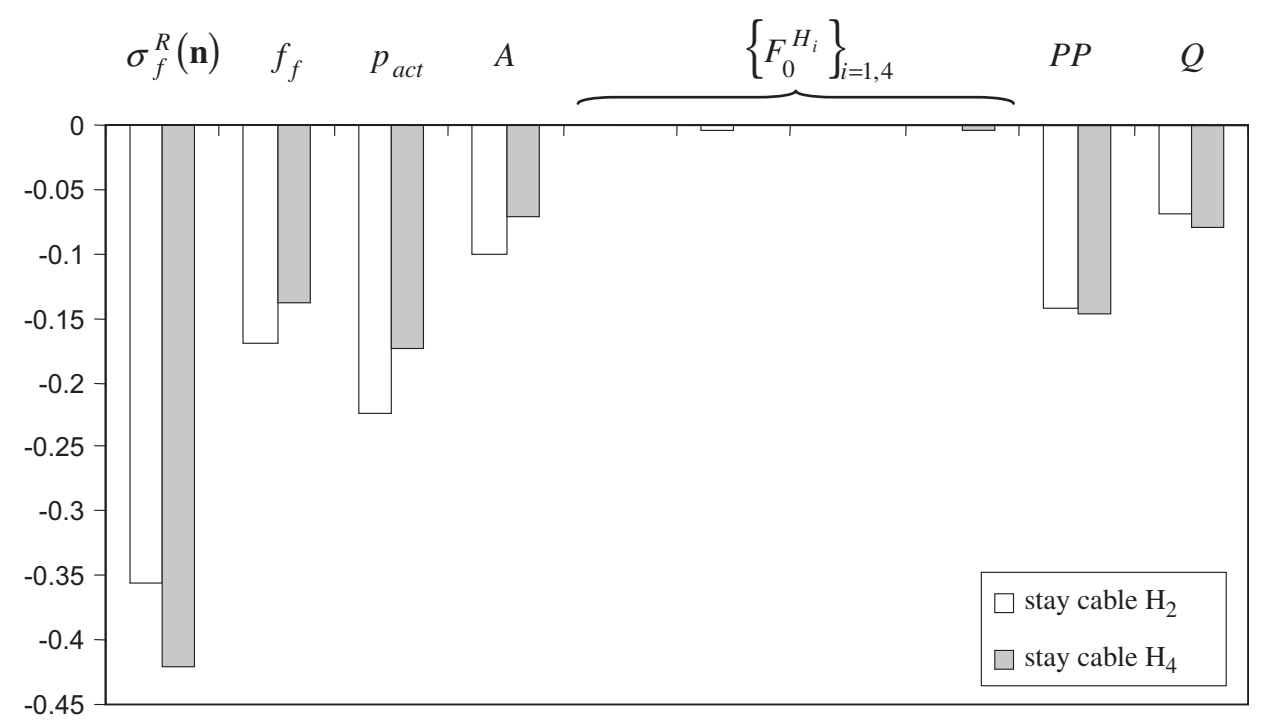

Fig. 9. Elasticities $e_{r_{i}}$ according to the standard deviation of random variables $\left(r_{i}=S_{X_{i}}\right)$. 


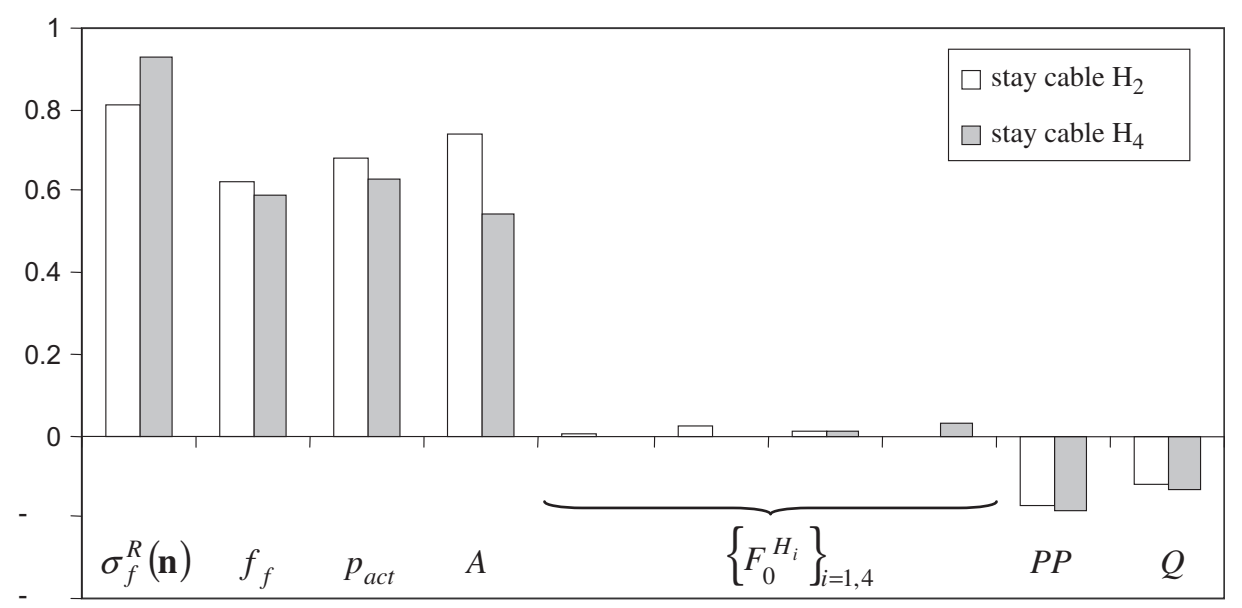

Fig. 10. Elasticities $e_{r_{i}}$ according to the mean value of random variables $\left(r_{i}=\bar{X}_{i}\right)$.

Table 3

Reliability index values according to microstructural modifications.

\begin{tabular}{llll}
\hline Kind of fibre & $\sigma_{f}^{R}(\mathbf{n})(\mathrm{MPa})$ & $f_{f}(\%)$ & $\beta_{\min }$ \\
\hline T700SC & 4870 & 67 & 67 \\
T300 & 3530 & 64 & $\mathrm{H}_{2}: 20.00 ; \mathrm{H}_{4}: 19.76$ \\
T700SC & 4870 & 60 & $\mathrm{H}_{2}: 14.75 ; \mathrm{H}_{4}: 14.39$ \\
T700SC & 4870 & $\mathrm{H}_{2}: 19.45 ; \mathrm{H}_{4}: 19.21$ \\
\hline
\end{tabular}

Table 4

Reliability index values according to the rod number.

\begin{tabular}{lll}
\hline Stay cables & Number of rods & $\beta$ \\
\hline $\mathrm{H}_{1}$ and $\mathrm{H}_{2}$ & $2 \times 7$ & $\mathrm{H}_{2}: 20.00 ; \mathrm{H}_{4}: 19.76$ \\
$\mathrm{H}_{3}$ and $\mathrm{H}_{4}$ & $3 \times 7$ & $\mathrm{H}_{2}: 14.36 ; \mathrm{H}_{4}: 19.97$ \\
$\mathrm{H}_{1}$ and $\mathrm{H}_{2}$ & $1 \times 7$ & \\
$\mathrm{H}_{3}$ and $\mathrm{H}_{4}$ & $3 \times 7$ & $\mathrm{H}_{2}: 18.73 ; \mathrm{H}_{4}: 15.26$ \\
$\mathrm{H}_{1}$ and $\mathrm{H}_{2}$ & $2 \times 7$ & $\mathrm{H}_{2}: 13.11 ; \mathrm{H}_{4}: 15.39$ \\
$\mathrm{H}_{3}$ and $\mathrm{H}_{4}$ & $2 \times 7$ & \\
$\mathrm{H}_{1}$ and $\mathrm{H}_{2}$ & $1 \times 7$ & \\
$\mathrm{H}_{3}$ and $\mathrm{H}_{4}$ & $2 \times 7$ & \\
\hline
\end{tabular}

The coupling with micromechanical modelling allows first to study the effect of microstructural modifications. According to sensitivity results given in Fig. 10, we propose to modify the kind of fibres used (that is with a different fibre tensile strength $\sigma_{f}^{R}(\mathbf{n})$ ) and the fibre volume fraction $f_{f}$. Results are presented in the Table 3 with TORAYCA T 300 fibres exhibiting a mean tensile strength $\sigma_{f}^{R}(\mathbf{n})$ of $3530 \mathrm{MPa}$ and for two average fibre volume fractions $f_{f}$ consistent with pultrusion process (60-64\%). Using the T 300 fibres type allows then a better optimization than reducing the fibres volume fraction: the reduction of index $\beta$ is more sensible to the kind of fibre ( 6 units less) rather than to the fibre volume fraction (only 1 or 2 units less).

Then, at the macroscopic scale, we propose to modify the number of strands used in each stay cable. Results presented in the Table 4 show the significant impact of various reduction of the section of stay cables (up to a decrease of 7 units less for the reliability index of cable $\mathrm{H}_{2}$ ).

These quite simple applications demonstrate the capacities of the coupled approach and the kind of information obtained by this way. While keeping possible the investigations at the macroscopic scale, we can indeed evaluate also the effects of microstructural parameters, which is not possible with classical purely macroscopic description of the composite mechanical behaviour.

\section{Conclusion}

This paper aimed at demonstrating the feasibility and interest of coupling micromechanical modelling and reliability analysis at a structure scale. Precisely, we provide a prototypical application on the Laroin footbridge of FORM reliability 
method employing the Mori-Tanaka scheme for cables and show how this combined approach allows to determine the effect of the cable composition and fibre parameters on the structural reliability. Through a step study (from material to structure level) and the use of reliability approximation method, it was indeed possible to account for various kinds of uncertainties at the microscopic and macroscopic scales and introduce a large number of relevant design variables, while keeping reasonable simulation times.

Even if simplifications have been considered in the present case (monotonic loads, longitudinal loading, no scale effect, ...), we have shown here some new perspectives provided by such a methodology in order to ensure a reliability level, measure the consequences of design choices or make significant improvements on structural weight and cost. Insofar as required experimental data are available, huge perspectives can be considered, in particular the study of other micromechanical schemes (self-consistent, differential, ...) or the extent to other failure modes (fatigue, durability, ...) and damage behaviour (with fibre loading transfer for instance).

\section{Acknowledgments}

Authors greatly acknowledge the FREYSSINET company based in Vélizy Villacoublay (France, Ile de France) and the SOFICAR company based in Abidos (France, Aquitaine) for providing technical data respectively on the Laroin footbridge and on the composite material. Special thanks also to Professor Moussa KARAMA of the National School of Engineers of Tarbes (ENIT) who made this work possible.

\section{References}

[1] Hollaway LC. The evolution of and the way forward for advanced polymer composites in the civil infrastructure. Constr Build Mater 2003;17:365-78.

[2] Ditlevsen O, Madsen H. Structural reliability analyses. Chichester: Wiley \& Sons; 1996.

[3] Lemaire M. Structural reliability. London: Wiley-ISTE; 2008.

[4] Gilormini P, Bréchet Y. Syntheses: mechanical properties of heterogeneous media: which material for which model? Which model for which material? Model Simul Mater Sci Eng 1999;7:805-16.

[5] Nemat-Nasser S, Hori M. Micromechanics: overall properties of heterogenous materials. Amsterdam: Elsevier; 1993.

[6] Bornert M, Bretheau T, Gilormini P. Homogenization in mechanics of materials. London: Wiley \& Sons; 2009.

[7] Dehmous H. Fiabilité et micromécanique des matériaux composites - Application à la passerelle de Laroin. Ph.D Thesis, INP Toulouse, France; 2007.

[8] Geffroy RL. La passerelle de Laroin. FREYSSINET magazine 2002:214

[9] FREYSSINET. Passerelle piétonne de Laroin - Document technique et note de calcul. Technical report; 2001.

[10] Berthelot JM. Composite materials - mechanical behavior and structural analysis. New York: Springer-Verlag; 1999.

[11] Miracle DB, Donaldson SL. ASM Handbook, Composites, vol. 21. ASM International; 2001.

[12] Benveniste Y. A new approach to the application of Mori-Tanaka's theory in composite materials. Mech Mater 1987;6:147-57.

[13] Haukaas L. FERUM user's guide. Berkley: University of California; 2000.

[14] Foret G, Ehrlacher A, Sab K. Etude probabiliste de la rupture des composites unidirectionnels - application aux câbles de précontrainte. Rev Comp Mater Adv 1998;8:121-35. 